\title{
The Influence Of Specialized Physical Education Program For Students With Health Issues
}

\author{
Dao Chanh Thuc ${ }^{\star \dagger}$ \\ Physical Education Deparment, An Giang University, VIETNAM \\ DOI: https://doi.org/10.15520/ijmhs.v9i2.2444
}

Accepted 20 Feb 2019; Received 28 Jan 2019; Publish Online 28 Feb 2019

\author{
Reviewed By: Dr. \\ Daniel V. \\ Department: Medical
}

\begin{abstract}
This study, the aim is to improve the School's Physical education process through the application of the Physical education program to students with health problems for a year. Its Influence is followed through changes, arising in heart rate after performing a therapeutic complex with kinesi. It is applied at the beginning and end (Tests I and II) of the study is carried out and consists of 32 exercises, divided into three parts: Prepare with general exercises, Main sections with a combination of lessons from different physical education subjects, coordinating with key groups established with students and the final section.

We examined the pulse rate as a reliable indicator for the level of motor suitability of a certain individual, as well as for the absence of training effect of the systematic activities with the program "Physical education for Students with Health Issues".

The kinesiotherapy complex is accurately dosage and conducted, which is indicative from the raising of the physiological curve; it can be performed by all students, regardless of their disease and it may be used for entry or exit testing [1] .

The training of students in specialized programs has positively affected them in the following directions:

- Achievements are changes in position function in the operation of the cardiovascular system of students, expressed by heart rate;

- Increasing is the vitality that stimulates the recovery process, normalizes the reaction to increase the tolerance of the organism;

- Improving circulation of separate agencies and systems;

- Increase the physical ability of the whole organism;

- Adjust the emotional state: provide energy, soothe, relax and relieve stress.
\end{abstract}

Key words: pulse frequency-students-kinesiotherapy complex-higher school

\section{INTRODUCTION}

The data of the final researches of experts disclose certain tendency for increasing disease rate among students: problematic are respiratory, cardiovascular and digestive systems, metabolic processes reported are also some psychiatric disorders [1] . As one of the main tools for fighting those diseases I. Researchers claim preventive treatment and improve social, labor, learning and health care conditions. The author concludes that systemic physical, physical education and tourism exercises are one of the main factors that lead to a high degree of adaptability of organisms with the most pronounced effect increasing the disease resistance, leading

\footnotetext{
* Corresponding author.

$\dagger$ Email: thuchus(at)gmail.com.
}

to improved quality of life [1] .

Many authors, examining the motor activity of students $[2,3]$ establish the lowest degree of motor activity and more strongly expressed tendency as its decrease for female students compared to male ones. Formed are also tendencies to groundless release from the physical education classes at universities [4] .

Dao C.T, A (2018) [5] confirms the relationship between the level of student activity and the quality of the general education process. Students with higher mobility are not only more likely to work physically and mentally but are also less likely to be absent due to certain diseases that reflect the level of positive use of school materials. 


\section{The Influence Of Specialized Physical Education Program For Students With Health}

2 TZAROVA (2013) AND A. TSAROVA \& VASILEVA (2013) [6] EXAMINE THE POSSIBILITIES OF THE CARDIOVASCULAR SYSTEM FOR ADAPTATION TO PHYSICAL EXERCISES WITH THE MEANS OF BASKETBALL, SWIMMING AND TOURISM WITH STUDENTS.

Various authors establish that in universities in the country enrolled are students having very low possibilities for adaptation of the cardiovascular system to physical exercising and very low functional condition [6]. The comparative analysis of results of athletes in various physical education disciplines between those doing physical education and those do not doing physical education, give an opportunity to disclose specific peculiarities of developing the functional possibilities [5, 7] .

The stated facts motivated us to develop the program "Physical education for Students with Health Issues" in order to cover all groups of students, including those with temporary or permanent diseases. Specialized program is coordinated with the individual diseases of students and adapted to the school process at Medical University-Ho Chi Minh City-Vietnam in discipline Physical education. It consists of two parts (for two semesters) with total hours of 60 academic hours.

Every semester contains 15 academic weeks, 2 academic hours per week with duration - 45 minutes. We set a goal of the research to perfect the academic process in Physical education discipline for students with health problems through applying specialized program. In order to follow its Influence through changes which incur in the pulse rate, after the execution of the kinesiotherapy complex.

The study is held in the beginning (September/2017) and the end (May/2018) of the academic year 2017/18. Participants are 39 students from the Medical University - Ho Chi Minh City-Vietnam (19 girls and 20 boys), I and II course at the age from 18 to 22 .

All of them have established by a physician temporary or permanent health issues, of which bone-joinery - 14 students with lung diseases - 15 students with kidney problems - 10 with cardiovascular diseases.

At detailed analysis made in the groups, we have found out that there is no reason to recommend to those students to avoid participation in trainings in physical education and physical education, as the moderate motor activity for example is the best prophylaxis of bone-joinery problems. With the healthy individuals, it is enough to load efficiently the bone-muscle, as well as the cardio-vascular system for keeping the organism at good condition.

\section{METHOD OF PROCEEDING}

- Compiled to become another complex of Kinesi, according to the identified diseases will be performed by all students.

- Register pulse speed during the implementation of other materials complexes Kinesi.

- To be synthesized for comparative analysis of heart rate opportunities in trials I and II to establish the effects of specialized programs.

The Influence of the specialized program "Physical education for Students with Health Issues" we followed through kinesiotherapy complex through which we examined the dynamic of the pulse rate. It is applied in the end (I and II testing) of the study being conducted. The complex contains 29 exercises, distributed in three parts:

1. Preparatory part with general exercises and stretching - circles, bends, lifting, releasing, strokes, swishes, springing, steps. It lasts $\frac{1}{4}$ of the total volume of the activity (10 min.), includes 7 exercises.

2. The main part is a combination of various gymnastics disciplines coordinated with the established main groups of diseases for students. It has duration of $2 / 4$ of the total volume of activity ( $25 \mathrm{~min}$.), includes 15 exercises.

3 . The conclusive part is $\frac{1}{4}$ of the total volume of activity (10 min.) and includes 5 exercises. It aims to rewind, normalize the pulse and support the recovery processes in the organism.

Applied is the pulsometry method MY-H016 4-Channel Holter ECG Monitor System price of ECG machine. The TLC series DCG systems is composed of the ECG recorders, a computer system, a laser printer and the software. The recorder adopts PCB and SMD technology, build in flash storage media that increases its memory capacity. The sampling rate of $200,500,1000$ sampling sec has improved that quality of waveform. The software of the system is checked by AHA and MIT, which ensure its accuracy [1] .

Automatically reported, registered, memorized and reproduced are values of pulse rate of students - at rest (in the beginning of performing the complex), after exercising (in peak - the second half of the main part) and after recovery (in the end of the complex) [8] .

Generalization of the studied characteristics was assessed by mean arithmetic value, standard deviation and error of mean arithmetic. Confidence of differences between mean values was stated by Student's t-criterion.

Assessment of statistical hypothesizes based on $0.05 \%$ significance level. For statistical processing of data, we used licensed program (SPSS 20.0). Statistical analysis of the received results was conducted, considering recommendations on SPSS tables' usage for computer data analysis [8, 9] .

\section{RESULTS}

During the operation of the motor, the following pulse speed is required. This is one of the easiest, objectified reports and provides information indicators for the ability of organisms to load accordingly.

The study confirms that the therapeutic complex with kinesi observes the structure of motor activity is rigorously set and slightly increased to individual work areas for each student.

Table 1 , data for comparative analysis between pulse rate at rest (beats/min), pulse rate after loading (beats/min), pulse rate after recovery (beats/min) during I and II testing through Kinesiotherapy complex are presented. 
Table 1. Data for comparative analysis

\begin{tabular}{lllllll}
\hline \multirow{2}{*}{ No } & TEST & Testing I & Testing & Pt \\
& & M & SD & M & SD & \\
1 & & 93.2 & 10.5 & 78.8 & 8.9 & - \\
& $\begin{array}{l}\text { Pulse rate at rest } \\
\text { (beats/min) }\end{array}$ & & & & & $17.6^{* *}$ \\
& $\begin{array}{l}\text { Pulse rate after loading } \\
\text { (beats/min) }\end{array}$ & 134.3 & 16.7 & 120.4 & 17.9 & - \\
& $\begin{array}{l}\text { Pulse rate after } \\
\text { recovery (beats/min) }\end{array}$ & 99.3 & 11.1 & 91.2 & 17.1 & - \\
& & & & & $6.9^{*}$ \\
\hline
\end{tabular}

Note: ** - Pt $<0.05$; ${ }^{*}$ Pt $<0.01$.

\section{DICUSSION AND CONCLUSIONS}

Functional tests are a variety of physical but registered different physiological parameters such as heart rate, pulmonary ventilation, oxygen consumption, heart rate and others. The main advantage of these tests is the ability to assess not much of the neuromuscular system activity as well as the systems to ensure muscle activity (cardiovascular, respiratory, vestibular, etc.). These tests allow to obtain information for the functional status of the personality that does not reach the maximum load. Experts believe that to prevent the emergence of pathological conditions and the formation of chronic pathology with students with the necessary level of motor activity is the constant control of the functional state of the organism in The main stage of functional changes [1] . The pulse rate is a reliable indicator for the degree of training of a certain individual as well as for the presence or lack of training effect, resulting of systematic activities [1] .

The results showed that when the activity started (at rest), students had a higher heart rate than usual at this age when both tested. The average values at tests I and II are $93.2 \mathrm{bpm}$ and $78.8 \mathrm{bpm}$, respectively. This average tachycardia can be explained with a number of secondary factors such as stressful daily life in learning activities, transportation to the physical and emotional education center of upcoming physical education activities. come and others. It is noteworthy that the fact is that the driving force of the primary pulse in the test phase is characterized by a 17.6 bpm material reduction, supported with the necessary statistical honesty Table 1 . Reduce heart rate after exercising with $19.1 \mathrm{bpm}$ (from $134.3 \mathrm{bpm}$ to $120.4 \mathrm{bpm}$ ) suggesting improvement in cardiovascular activity due to the Physical Education program for students with problems health, during the study period.

A positive change arises in a statistically significant heart rate. It is currently economicizing the work of the cardiovascular system and the existence of training effectiveness (minimum heart rate provides effective training for children aged 18-22 years of $93.3 \mathrm{bpm}$ ). The complex pulse rate at the end (after recovery) decreased to $91.2 \mathrm{bpm}$ when testing II. The difference of $6.9 \mathrm{bpm}$ is not supported with the necessary statistical truthfulness Table 1 , which indicates the effect of other factors on cardiovascular activity resilience. Complexity is the correct dosage, built and kept because the increase in physiological curves is gradual and has the following characteristics: the largest increase of pulse, ie the peak of the physiological curve located in the second half of the main part (25- 30 minutes); the highest pulse peak does not exceed the pulse frequency greater than 75 to $100 \%$ of the measured frequency at rest; At the end of the conclusion, the pulse returns to the main level and exceeds about $10 \%$. This result is similar to the study of Bozhkova A, et al. (2017).

Complex therapy with kinesi is accurately quantified, built and organized, as indicated by the formation of an increase in physiological curves.

In summary, the training of PE students for students with health problems has positively affected them in the following ways:

Achievements are position function changes in the functioning of the cardiovascular system of students, expressed by heart rate; Increasing is the vitality that stimulates the recovery process, normalizes the reaction to increase the tolerance of the organism; Improving circulation of separate agencies and systems; Increase the physical ability of the whole organism; Adjust the emotional state: provide energy, soothe, relax and relieve stress.

\section{REFERENCES}

[1] L. Bozhkova A, Slavcheva P-Hinkova and Daniela. Journal of Physical Education and Sport. 2017;17(1):6.

[2] Dyakova G. Exemption of students from physical education classes - trends and forecasts. Sport and Science. 2006;4:7275.

[3] Ivanova A. Influence of aerobics classes on some functional parameters. Repertory, Personality, Motivation, Sports. $2009 ; 14: 262-264$.

[4] Bozhkova A. Sport programme for students with health issues. Conference; 2014. p. 149-152.

[5] Chatterjee S, Chatterjee P, Bandyopadhyay A. Validity of Queen's College step-test for estimation of maximum oxygen uptake in female students. Indian J Med Res. 2005;121:32-35.

[6] Tzarova R. Adaptation abilities of the cardiovascular system to physical loads by means of basketball, swimming and tourism within the conditions of the higher school. vol. 41. Skopje, Makedonia; 2013.

[7] Effect of physiotherapy and hippotherapy on kinematics of lower limbs during walking in patients with chronic low back pain: A pilot study. Journal of Physical Education and Sport, 15(4), Art. 2015;101:663-670.

[8] Dao C.T; 2018.

[9] Dao C.T, A (2018). The influence of physical activities on biological age parameters of females from 17 to 18 years old. Sports Medicine and Therapy Journal ISSN. 0;2573(1726):075-079.

\section{AUTHOR BIOGRAPHY}

Dao Chanh Thuc Physical Education Deparment, An Giang University, VIETNAM 